(P-ISSN : 2461-0577 ; E-ISSN : 2477-5347)

\title{
IMPLEMENTASI ZAKAT PRODUKTIF HIBAH MODAL DALAM MENINGKATKAN KESEJAHTERAAN MUSTAHIK MISKIN (STUDI PADA BAZNAS KOTA MOJOKERTO)
}

\author{
Ana Musta'anah ${ }^{1}$, Imam Sopingi ${ }^{2}$ \\ Ekonomi Islam, Fakultas Ekonomi, Universitas Hasyim Asy’ari, Jombang \\ mustaanah910@gmail.com
}

\begin{abstract}
Poverty is a much-discussed issue. Not the government does not care. However, many factors hinder the performance of government programs in poverty eradication. The existence of effective management of productive zakat is expected to reduce the existing poverty rate.The purpose of this research is to know the management pattern and the effect of Capital Grant Productive Tithe Management in Improving Prosperity of Poor Mustahik at Badan Amil Zakat Nasional (BAZNAS) Mojokerto. The research method used is qualitative approach by combining research type of phenomenology and case study. Data collection was conducted with interviews, direct participatory observation, and documentation. Data validity techniques used credibility techniques, internal validity, dependability, and confirmability (objectivity). Techniques of analysis by means of data reduction, presentation of data, and draw conclusions.The result of this research is the Capital Grant Productive Tithe Management still not able to improve prosperity of poor mustahik significantly both materially and spiritually. It can be seen from the income of four mustahik which is permanent status from the mustahik syrup sampled. Even from the spiritual side, the capital grant has not been able to improve the mustahic welfare. This can be seen from the absence of a spirituality change before and after getting a capital grant.
\end{abstract}

Key Word: Poverty, Productive Tithe Management, Capital Grant, Poor Mustahik Prosperity

\section{PENDAHULUAN}

Kesejahteraan merupakan salah satu tujuan yang ingin dicapai oleh suatu negara. Tetapi pada kenyataannya, tidak semua warga negara mampu merasakan kondisi tersebut. Tingkat kesejahteraan yang rendah akan menimbulkan beberapa permasalahan. Adapun permasalahan yang dimaksud 
(P-ISSN : 2461-0577 ; E-ISSN : 2477-5347)

di antaranya adalah kemiskinan dan pengangguran. Permasalahan kemiskinan dan pengangguran bukan tidak menjadi perhatian pemerintah. Pemerintah dengan berbagai program yang dilaksanakan berharap dapat mengurangi angka kemiskinan dan pengangguran di Indonesia. Namun pada pelaksanaannya, program yang diusahakan oleh pemerintah tersebut masih menemui kendala yang pada akhirnya menghambat tujuan pemerintah untuk mengurangi angka kemiskinan dan pengangguran di Indonesia (Larasati dan Adhittama, 2017: 58).

Keseriusan Islam untuk melepaskan umat Islam dari jerat kemiskinan secara berkala dan sistematis melalui zakat sebagai alat pengentas kemiskinan memunculkan berbagai alternatif baru. Praktek pengelolaan zakat sudah sejak lama dipraktikkan dan diregulasi langsung oleh Nabi Muhammad SAW (Rianto, 2012: 375). Islam memandang kemiskinan sebagai ancaman bagi iman seseorang (Wibisono, 2015: 22). Sebab kemiskinan merupakan masalah struktural yang akan memunculkan masalah baru, seperti tindak kriminalitas, melakukan hal yang melanggar batas Syari'ah. Sebagaimana Allah AWT berfirman (QS. 2 : 268)

Setan menjanjikan (menakut-nakuti) kemiskinan kepadamu dan menyuruh berbuat keji (kikir), sedangkan Allah menjanjikan ampunan dan karunia-Nya kepadamu. Dan Allah Maha Luas, Maha Mengetahui.

Potensi zakat nasional pada tahun 2011 diperkirakan mencapai angka Rp. 217 Triliun atau 3,4 dari jumlah Produk Domestik Bruto (PDB) (Firdaus at al, 2012). Sedangkan potensi Zakat, Infaq dan Shadaqah (ZIS) yang terkumpul di Kota Mojokerto sudah cukup besar yaitu Rp. 1.811.000.000 per tahun 2017 (Outlook BAZNAS Kota Mojokerto Tahun 2017). Jumlah angka kemiskinan yang ada di Kota Mojokerto pada tahun 2017 lalu mencapai 8.700 penduduk (mojokertokota.bps.go.id). Sedangkan Tingkat Pengangguran Terbuka (TPT) pada Agustus 2015 sebesar 4,88 persen (mojokertokota.bps.go.id). Jumlah dana ZIS yang terkumpul di BAZNAS Kota Mojokerto selanjutnya diharapkan mampu meningkatkan tingkat kesejahteraan mustaik miskin. Berdasarkan latar belakang di atas, tujuan dari penelitian ini adalah untuk mengetahui pola pengelolaan zakat produktif 
hibah modal dan dampaknya dalam meningkatkan kesejahteraan mustahik miskin.

\section{Kajian Pustaka}

\section{Zakat Produktif}

Makna zakat jika ditinjau dari lisan al-Arab dari sudut bahasanya, zakat berarti suci, tumbuh, berkah, dan terpuji. Semuanya digunakan di dalam al-Quran dan hadits (Qardhawi, 2007: 34). Sedangkan kata zakat secara istilah adalah sebuah nama bagi suatu harta tertentu, didapat (keluarkan) dari suatu harta tertentu, menurut cara tertentu, diberikan kepada sekelompok orang tertentu pula (AlGhazi, 2012). Sedangkan menurut Undang-Undang No. 23 tahun 2011 pasal 1, Zakat adalah harta yang wajib dikeluarkan oleh seorang muslim atau badan usaha untuk diberikan kepada yang berhak menerimanya sesuai dengan syariat Islam.

Pengertian zakat jika kita bertolak pada Al-Quran, zakat diartikan sebagai perbuatan yang akan membersihkan dan menyucikan. Hal ini sebagaimana tercantum dalam Q.S. Al-Taubah (9): 103
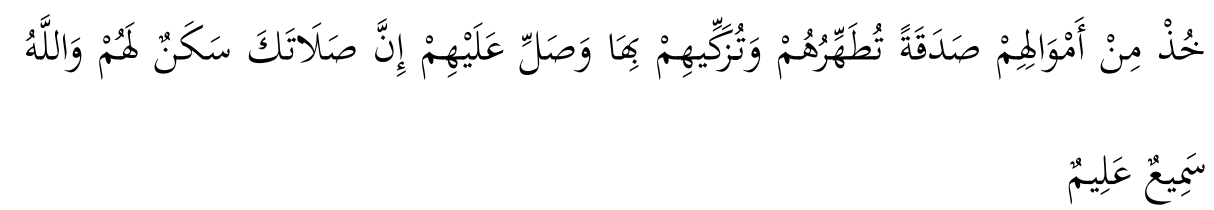

Ambillah zakat dari harta mereka, guna membersihkan dan mensucikan mereka, dan berdo'alah untuk mereka. Sesungguhnya do'amu itu (menumbuhkan) ketentraman jiwa bagi mereka. Allah maha mendengar, maha mengetahui

Ayat di atas menjelaskan bahwa sebagai manusia yang mengakui dosanya, sudah sewajarnya melakukan pembersihan diri dari noda, dan sebab utama ketidakikutsertaan meraka dalam medan perang adalah keinginan untuk bersenang-senang dengan harta yang mereka miliki, atau harta yang dimiliki menjadi penghalang keberangkatan mereka dalam medan juang. Maka atas dasar itu Allah SWT 
(P-ISSN : 2461-0577 ; E-ISSN : 2477-5347)

memerintahkan Nabi Muhammad SAW mengambil harta mereka dan diberikan kepada mereka yang berhak (Shihab, 2007: 706).

Kata produktif menurut Kamus Besar Bahasa Indonesia (KBBI) produktif artinya bersifat atau mampu menghasilkan (dalam jumlah besar): perkebunan itu sangat--; mendatangkan (memberi hasil, manfaat, dan sebagainya); menguntungkan: tabungan masyarakat dapat dipinjamkan kembali untuk keperluan.

Perintah mengeluarkan zakat ini merupakan bukti bahwa agama Islam mengecam kesenjangan sosial dan ekonomi yang terjadi di tengah-tengah masyarakat. Atas dasar itu, zakat menjadi solusi ynag ditawarkan Islam untuk menutup kesenjangan tersebut dan melakukan pemerataan pendapatan di kalangan masyarakat. Kewajiban untuk mengeluarkan zakat ini terabadikan dalam sebuah Hadits Nabi Muhammad SAW.

عن ابن عباس أنّ رسول الله صلّى الله عليه وسلّم لما بعث معا ذا إلى اليمن قال: إِنَّكَّ

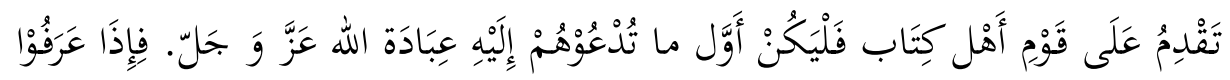

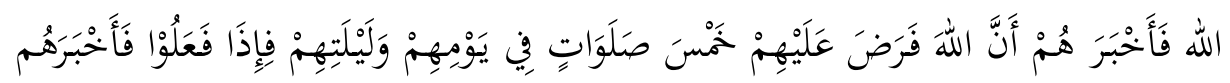

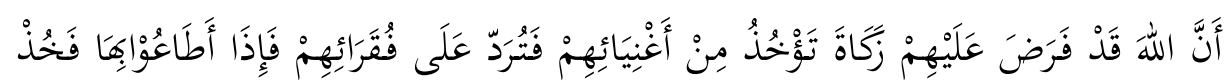

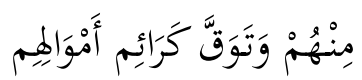

Lewat jalur lain dari sumber Ibnu Abbas, diriwayatkan bahwa Rasulullah SAW. ketika mengutus Mu'adz ke Yaman, beliau bersabda: Engkau akan datang pada suatu kaum Ahli Kitab. Karena itu, hendaknya yang pertama-tama engkau serukan kepada mereka ialah beribadah kepada Allah Azza wa Jalla. Apabila mereka telah mengenal Allah, maka beritahulah mereka bahwa Allah mewajibkan kepada mereka shalat lima waktu dalam sehari semalam. Kalau mereka sudah mau mengerjakan, maka beritahulah mereka bahwa Allah mewajibkan atas mereka zakat yang diambil dari orang-orang kaya mereka dan diberikan kepada fakir-miskin mereka. Bila mereka menaatinya, maka ambillah dari mereka dan waspadalah terhadap harta pilihan mereka. (HR. Muslim, hadits no. 31)

Pola pendistribusian zakat dalam Buku Pedoman Zakat yang diterbitkan Ditjen Bimas Islam dan Urusan Haji Departemen Agama, untuk pendayagan dana zakat, bentuk inovasi distribusi dikategorikan dalam empat bentuk berikut (Mufraini, 2008: 153).

1) Distribusi bersifat 'konsumtif tradisional', yaitu zakat dibagikan kepada mustahik untuk dimanfaatkan secara langsung, seperti zakat 
(P-ISSN : 2461-0577 ; E-ISSN : 2477-5347)

fitrah yang diberikan kepada fakir miskin untuk memenuhi kebutuhan sehari-hari atau zakat mal yang dibagikan kepada para korban bencana alam.

2) Distribusi bersifat 'konsumtif kreatif', yaitu zakat diwujudkan dalam bentuk lain dari barangnya semula, seperti diberikan dalam bentuk alat-alat sekolah atau beasiswa.

3) Distribusi bersifat 'produktif tradisional', dimana zakat diberikan dalam bentuk barang-barang yang produktif seperti kambing, sapi, alat cukur, dan lain sebagainya. Pemberian dalam bentuk ini akan dapat menciptakan suatu usaha yang membuka lapangan kerja bagi fakir miskin.

4) Distribusi dalam bentuk 'produktif kreatif'. Yaitu zakat diwujudkan dalam bentuk permodalan baik untuk membangun proyek sosial atau menambah modal pedagang pengusaha kecil.

Dalam hal ini kata produktif disandingkan dengan kata zakat, sehingga dapat disimpulkan bahwa zakat produktif adalah sejumlah dana yang terkumpul dari muzakki yang selanjutnya akan didistribusikan kepada mustahiq dalam bentuk modal langsung atau dalam bentuk barang-barang produktif.

\section{Pengelolaan}

Pengelolaan pada Badan Amil Zakat Nasional (BAZNAS) sebagaimana tertera dalam Undang-Undang Nomor 23 Tahun 2011 Tentang Pengelolaan Zakat. Dalam Pasal 1 Ayat 1 Undang-Undang Nomor 23 Tahun 2011 yang dimaksud dengan Pengelolaan Zakat adalah kegiatan perencanaan, pelaksanaan, dan pengoordinasian dalam pengumpulan, pendistribusian, dan pendayagunaan zakat. kegiatan perencanaan, pelaksanaan, dan pengoordinasian dalam pengumpulan, pendistribusian, dan pendayagunaan zakat.

Pengelolaan zakat harus berasaskan pada syariah islam, amanah, kemanfaatan, keadilan, kepastian hukum, terintegrasi dan akuntabilitas. Hal tersebut sebagaimana tercantum dalam Pasal 2 Undang-Undang Nomor 23 Tahun 2011 Tentang Pengelolaan Zakat. Selain itu, pengelolaan zakat 
(P-ISSN : 2461-0577 ; E-ISSN : 2477-5347)

memiliki tujuan yaitu untuk meningkatkan efektivitas dan efesiensi pelayanan dalam pengelolaan zakat dan meningkatkan manfaat zakat untuk mewujudkan kesejahteraan masyarakat penanggulangan kemiskinan. hal tersebut sebagaimana tercantum dalam Pasal 3 Undang-Undang Nomor 23 Tahun 2011 Tentang Pengelolaan Zakat.

BAZNAS merupakan lembaga ynag berwenang melakukan tugas pengelolaan zakat secara nasional. Hal tersebut sebagaimana tertera dalam Pasal 6 Undang-Undang Nomor 23 Tahun 2011 Tentang Pengelolaan Zakat. Dalam Pasal 7 diuraikan bagaimana tugas BAZNAS untuk mampu merealisasikan yang tercantum dalam Pasal 6, maka BAZNAS harus menyelenggarakan fungsi yang tercantum dalam Pasal 7.

(1) Dalam melaksanakan tugas sebagaimana dimaksud dalam Pasal 6, BAZNAS menyelenggarakan fungsi:

a. perencanaan pengumpulan, pendistribusian, dan pendayagunaan zakat;

b. pelaksanaan pengumpulan, pendistribusian, dan pendayagunaan zakat;

c. pengendalian pengumpulan, pendistribusian, dan pendayagunaan zakat; dan

d. pelaporan dan pertanggungjawaban pelaksanaan pengelolaan zakat.

(2) Dalam melaksanakan tugas dan fungsinya, BAZNAS dapat bekerja sama dengan pihak terkait sesuai dengan ketentuan peraturan perundang-undangan.

(3) BAZNAS melaporkan hasil pelaksanaan tugasnya secara tertulis kepada Presiden melalui Menteri dan kepada Dewan Perwakilan Rakyat Republik Indonesia paling sedikit 1 (satu) kali dalam 1 (satu) tahun. 
(P-ISSN : 2461-0577 ; E-ISSN : 2477-5347)

\section{Kesejahteraan}

Kata sejahtera dalam Kamus Besar Bahasa Indonesia diartikan sebagai aman, sentosa, dan makmur, selamat (terlepas dari segala macam ganguan kesukaran dan sebagainya). Sedangkan kata kesejahteraan adalah keadaan sejahtera yang meliputi keamanan, keselamatan, ketentraman.

Menurut pasal 1 ayat 1 Undang-Undang Nomor 11 Tahun 2009 tentang kesejahteraan sosial. Kesejahteraan sosial adalah kondisi terpenuhinya kebutuhan material, spiritual, dan sosial warga negara agar dapat hidup layak dan mampu mengembangkan diri, sehingga dapat melaksanakan fungsi sosialnya.

Pemikiran terkait kesejahteraan atau sosial ekonomi yang dikembangkan oleh Al-Ghazali bertolak dari sebuah konsep "fungsi kesejahteraan sosial". Dalam hal ini, yang dimaksud dengan konsep fungsi kesejahteraan sosial adalah konsep maslahah dalam Islam. Yakni sebuah konsep yang mencakup semua aktivitas manusia dan membuat kaitan yang erat antara individu dengan masyarakat.

Menurut Al-Ghazali, kesejahteraan (maslahah) dari suatu masyarakat tergantung kepada pencairan dan pemeliharaan lima tujuan dasar, yakni agama (al-dien), hidup atau jiwa (nafs), keluarga atau keturunan (nasl), harta atau kekayaan (mal), dan intelek atau akal ('aql) (Karim, 2010: 318). Kesejahteraan bukan hanya diukur dari materil saja, kesejahteraan perlu diukur dari sisi spiritual pula. Kebutuhan spiritual minimal adalah terkait dengan hal-hal pokok yang harus dipenuhi oleh masyarakat terkait dengan kewajiban agama. Sebagaimana diketahui bahwa shalat, puasa dan zakat adalah termasuk rukun Islam yang wajib untuk dilaksanakan. Kualitas keimanan antara lain ditentukan oleh komitmen untuk melaksanakan ibadah-ibadah tersebut. Oleh sebab itu, batasan garis kesejahteraan spiritual adalah pada melaksanakan shalat wajib lima waktu, melaksanakan puasa Ramadhan dan membayar zakat bagi yang mampu atau minimal berinfak sekali dalam satu tahun (Beik dan Laily Dwi Arsyianti, 2017: 78). 
(P-ISSN : 2461-0577 ; E-ISSN : 2477-5347)

\section{Metode Penelitian}

Untuk menjawab permasalahan yang telah dirumuskan dalam pendahuluan, digunakan pendekatan penelitian kualitatif. Menurut Bogdan dan Taylor (1975) dalam Ahmadi (2016: 15) metode kualitatif adalah prosedur penelitian yang menghasilkan data deskriptif. Sedangkan jenis penelitian ini menggunakan jenis penelitian fenomenologi (Iskandar, 2010) pendekatan yang berorientasi untuk memahami, menggali dan menafsirkan peristiwa-peristiwa dengan orang yang biasa dalam situasi tertentu dan studi kasus.

Sumber primer diperoleh dari wawancara bersama pegawai BAZNAS dan mustahik penerima hibah modal, observasi partisipatif, dan dokumen dari lembaga tempat penelitian. Adapun jumlah mustahik miskin yang dibutuhkan dalam penelitian ini adalah sepuluh mustahik miskin. Hal tersebut dikarenakan jenis penelitian yang digunakan oleh penulis salah satunya adalah jenis penelitian fenomenologi yang menggunakan sepuluh informan untuk mewakili populasi penelitian (Kuswarno, 2009: 62). Sedangkan sumber data sekunder diperoleh dari buku-buku, kitab-kitab, jurnal dan tulisan yang berkaitan dengan penelitian. Setelah data terhimpun, selanjutnya akan dianalisis dengan teknik induktif, deduktif dan deskriptif.

\section{HASIL DAN PEMBAHASAN}

Pengelolaan dalam penelitian ini adalah sebagaimana yang tercantum dalam Undang-Undang No 23 Tahun 2011 tentang Pengelolaan Zakat. pengelolaan dalam hal ini meliputi kegiatan perencanaan, pelaksanaan, dan pengoordinasian atau pengendalian dalam pengumpulan, pendistribusian dan pendayagunaan.

Perencanaan adalah strategi yang dilakukan oleh Baadan Amil Zakat Nasional (BAZNAS) Kota Mojokerto dalam menjalankan kegiatan pengumpulan, pendistribusian dan pendayagunaan zakat. struktur organisasi yang telah disesuaikan dengan Undang-Undang Nomor 23 Tahun 2011 Bab II 
(P-ISSN : 2461-0577 ; E-ISSN : 2477-5347)

Pasal 8 dan Peraturan BAZNAS Nomor 3 tentang Organisasi BAZNAS Provinsi dan BAZNAS Kabupaten Kota.

Undang-Undang Nomor 23 Tahun 2011 tentnag Pengelolaan Zakat Bab III Pasal 23 Ayat 1 dijelaskan bahwa BAZNAS atau LAZ wajib memberikan bukti setor zakat kepada setiap muzakki yang kemudian bukti setor tersebut akan berfungsi sebagai pengurang penghasilan kena pajak. Adapun dalam melakukan pengumpulan dana zakat, BAZNAS bekerjasama dengan instansi yang ada di Kota Mojokerto, baik instansi pendidikan, pemerintahan maupun perusahaan. Hal tersebut sesuai dengan Peraturan Wali Kota No 14 Tahun 2013 tentang Pedoman Teknis Pemungutan Zakat Pendapatan Bab IV Pasal 6 Ayat 1 Sebelum mela ksanakan pemungutan, Badan Pelaksana membentuk UPZ pada masing-masing Satuan Kerja Perangkat Daerah, BUMD/BUMN, Intansi Vertikal, dan Badan. Selain itu, BAZNAS Kota Mojokerto telah melaksanakan pendistribusian dana zakat dalam bentuk usaha produktif. Salah satu bentuk program tersebut adalah program hibah modal.

BAZNAS Kota Mojokerto sejauh ini masih belum mampu menjalankan fungsi pengendalian yang dimaksudkan dalam Undang-Undang No 23 Tahun 2011 Bab II Pasal 7 Ayat 1 Poin c tersebut secara maksimal. Hal tersebut disebabkan kurangnya tenaga atau pegawai yang bertugas untuk melakukan pengawasan dan pengandilan terhadap mustahik yang telah menerima program hibah modal.

Kegiatan-kegiatan yang telah dijalankan oleh BAZNAS Kota Mojokerto pada akhirnya akan dipublikasan dalam bentuk sistem pelaporan SiMBA BAZNAS, laporan triwulan, laporan tahunan dan majalah al-ashnaf. Sesuai dengan ketentuan pasal 9 ayat (1) Peraturan Daerah Kota Mojokerto Nomor 3 Tahun 2010, bahwa Badan Amil Zakat Nasional dalam melaksanakan tugasnya bertanggungjawab kepada Pemerintah Kota, Dewan Perwakilan Rakyat Daerah (DPRD) dan masyarakat muslim dalam bentuk laporan rutin dan tahunan (Laporan BAZNAS Tahun 2017).

Pelaporan atau publikasi pelaksanaan kegiatan yang dilakukan oleh BAZNAS Kota Mojokerto jika diselaraskan dengan Undang-Undang No 23 
(P-ISSN : 2461-0577 ; E-ISSN : 2477-5347)

Tahun 2011 Bab II Pasal 7 Ayat 3 yang menyatakan bahwa BAZNAS melaporkan hasil pelaksanaan tugasnya secara tertulis kepada Presiden melalui Menteri dan kepada Dewan Perwakilan Rakyat Republik Indonesia (DPR RI) paling sedikit 1 (satu) kali dalam 1 (satu) tahun. Namun dalam hal ini, BAZNAS Kota Mojokerto belum mampu merealisasikan isi yang dimaksud dalam Undang-Undang tersebut.

Potensi zakat dalam mengentas kemiskinan yang ada telah disadari oleh pemerintah. Hal tersebut melatarbelakangi munculnya inovasi-inovasi baru dalam pengelolaan zakat guna mengurangi angka kemiskinan yang ada. Program hibah modal yang dilakukan oleh BAZNAS Kota Mojokerto menjadi salah satu bukti kehendak pemerintah mengurangi angka kemiskinan dan meningkatkan kesejahteraan mustahik miskin.

Tolak ukur untuk menampilakan dampak dari pengelolaan zakat produktif dalam upaya meningkatkan kesejahteraan mustahik miskin dapat dilihat dari pendapatan mustahik miskin yang telah mencapai minimum pendapatan per kapita perbulannya (Ekomah, 2017). Hal tersebut merupakan penilaian kesejahtera dari sisi material. Adapun dari sisi spiritual, penulis akan melihat aktif atau tidaknya mustahik miskin dalam menjalankan kewajiban shalat, puasa dan infak setidaknya satu kali dalam seumur hidup (Beik dan Laily Dwi Arsyianti, 2017: 78-79). Penyajian data yang ditampilkan dalam hasil penelitian ini merupakan adopsi dan kolaborasi dari bentuk penyajian penelitian yang dilakukan oleh Bagus Imam Sodikun (Sodikun, 2017) dan Asma Karimah (Karimah, 2017).

Tabel 4.3

\section{Hasil Peningkatan Pendapatan Sebelum dan Sesudah Menerima Hibah}

\section{Modal}

\begin{tabular}{|l|c|c|c|c|}
\hline No & Nama & Pendapatan & Pendapatan & Kondisi Ekonomi \\
& & Sebelum & Sesudah & Setelah Menerima \\
& & Menerima & Hibah & Hibah Modal \\
& & Hibah & Modal & \\
& Modal & (Per-hari) & \\
& & (Per-hari) & & \\
\hline
\end{tabular}


ZISWAF; Jurnal Zakat dan Wakaf ( 2019, Vol. 6 No. 1)

(P-ISSN : 2461-0577 ; E-ISSN : 2477-5347)

\begin{tabular}{|c|c|c|c|c|c|}
\hline & & $\mathrm{Rp}$ & $\mathrm{Rp}$ & Tetap & Membaik \\
\hline 1 & Roestiyowati & $\begin{array}{l}30.000- \\
40.000\end{array}$ & $\begin{array}{l}50.000- \\
60.000\end{array}$ & & $\sqrt{ }$ \\
\hline 2 & Warsinah & 35.000 & 40.000 & & $\sqrt{ }$ \\
\hline 3 & Huda Watini & $\begin{array}{l}5.000- \\
10.000\end{array}$ & $\begin{array}{l}10.000- \\
15.000\end{array}$ & & $\sqrt{ }$ \\
\hline 4 & Nanang Boenari & 100.000 & 150.000 & & $\sqrt{ }$ \\
\hline 5 & $\begin{array}{l}\text { Saifuddin } \\
\text { Annafabi }\end{array}$ & 200.000 & 250.000 & & $\sqrt{ }$ \\
\hline 6 & Bunari & 50.000 & 50.000 & $\sqrt{ }$ & \\
\hline 7 & Dulatim & $\begin{array}{l}30.000- \\
40.000\end{array}$ & $\begin{array}{l}30.000- \\
40.000\end{array}$ & $\sqrt{ }$ & \\
\hline 8 & Sampurno & 50.000 & 60.000 & & $\sqrt{ }$ \\
\hline 9 & Paimah & 53.000 & 53.000 & $\sqrt{ }$ & \\
\hline 10 & Rimah & 150.000 & 150.000 & $\sqrt{ }$ & \\
\hline
\end{tabular}

Sumber : Data Primer (Hasil Wawancara)

Dari diagram di atas, dapat disimpulkan bahwa peningkatan pendapatan sebelum dan sesudah menerima hibah modal tidak begitu signifikan. mustahik yang dijadikan informan dalam penelitian ini sejumlah sepuluh orang untuk menggali informasi terkait masalah yang diteliti. Mustahik yang telah menerima hibah modal hanya enam puluh persen yang masuk dalam kategori membaik, sedang empat puluh persen masuk dalam kategori tetap.

Indikator kondisi spiritual yang dimaksudkan dalam penelitian ini adalah pelaksanaan sholat lima waktu, puasa Ramadhan dan minimal dalam setahun pernah mengeluarkan infak (Beik dan Laily Dwi Arsyianti, 2017: 7879). Kondisi spiritual mustahik dikatakan "aktif” apabila mustahik melakukan seluruh indikator kondisi spiritual (Ramadhanu, 2016). Mustahik dikatakan "tidak aktif" dilihat dari pelaksanaan sholat lima waktu mustahik apakah ada yang ditinggalkan, apakah mustahik menjalankan puasa Ramdhan secara penuh dan mengeluarkan infak setidaknya sekali dalam satu tahun. Penyajian data dalam penelitian terkait kondisi spiritual ini merupakan adopsi dari 
ZISWAF; Jurnal Zakat dan Wakaf ( 2019, Vol. 6 No. 1)

(P-ISSN : 2461-0577 ; E-ISSN : 2477-5347)

bentuk penyajian data hasil penelitian yang dilakukan oleh Andika Ramadhanu (Ramadhanu, 2016).

Tabel 4.4

Kondisi Spiritual Mustahik Miskin Sebelum dan Sesudah Menerima Hibah Modal

\begin{tabular}{|c|c|c|c|c|c|c|c|}
\hline No & Nama & \multicolumn{6}{|c|}{ Tingkat Ibadah } \\
\hline & & \multicolumn{2}{|c|}{ Sholat } & \multicolumn{2}{|c|}{ Puasa } & \multicolumn{2}{|c|}{ Infak } \\
\hline & & SB & SD & SB & SD & SB & SD \\
\hline 1 & Roestiyowati & $\begin{array}{l}\text { Tidak } \\
\text { Aktif }\end{array}$ & $\begin{array}{l}\text { Tidak } \\
\text { Aktif }\end{array}$ & Aktif & Aktif & Aktif & Aktif \\
\hline 2 & Warsinah & Aktif & Aktif & Aktif & Aktif & Aktif & Aktif \\
\hline 3 & Huda Watini & Aktif & Aktif & Aktif & Aktif & Aktif & Aktif \\
\hline 4 & $\begin{array}{l}\text { Nanang } \\
\text { Boenari }\end{array}$ & Aktif & Aktif & Aktif & Aktif & Aktif & Aktif \\
\hline 5 & $\begin{array}{l}\text { Saifuddin } \\
\text { Annafabi }\end{array}$ & Aktif & Aktif & Aktif & Aktif & Aktif & Aktif \\
\hline 6 & Bunari & $\begin{array}{l}\text { Tidak } \\
\text { Aktif }\end{array}$ & $\begin{array}{l}\text { Tidak } \\
\text { Aktif }\end{array}$ & $\begin{array}{l}\text { Tidak } \\
\text { Aktif }\end{array}$ & $\begin{array}{l}\text { Tidak } \\
\text { Aktif }\end{array}$ & Aktif & Aktif \\
\hline 7 & Dulatim & Aktif & Aktif & Aktif & Aktif & Aktif & Aktif \\
\hline 8 & Sampurno & Aktif & Aktif & Aktif & Aktif & Aktif & Aktif \\
\hline 9 & Paimah & $\begin{array}{l}\text { Tidak } \\
\text { Aktif }\end{array}$ & $\begin{array}{l}\text { Tidak } \\
\text { Aktif }\end{array}$ & $\begin{array}{l}\text { Tidak } \\
\text { aktif }\end{array}$ & $\begin{array}{l}\text { Tidak } \\
\text { Aktif }\end{array}$ & $\begin{array}{l}\text { Tidak } \\
\text { Aktif }\end{array}$ & $\begin{array}{l}\text { Tidak } \\
\text { Aktif }\end{array}$ \\
\hline 10 & Rimah & $\begin{array}{l}\text { Tidak } \\
\text { Aktif }\end{array}$ & $\begin{array}{l}\text { Tidak } \\
\text { Aktif }\end{array}$ & $\begin{array}{l}\text { Tidak } \\
\text { Aktif }\end{array}$ & $\begin{array}{l}\text { Tidak } \\
\text { Aktif }\end{array}$ & $\begin{array}{l}\text { Tidak } \\
\text { Aktif }\end{array}$ & $\begin{array}{l}\text { Tidak } \\
\text { Aktif }\end{array}$ \\
\hline
\end{tabular}

Sumber Primer : Wawancara Mustahik Miskin

Keterangan:

SB : Sebelum mendapatkan hibah modal

SD : Sesudah mendapatkan hibah modal

Tabel di atas memaparkan bahwa pemberian hibah modal tidak memiliki dampak apapun terhadap kondisi spiritual mustahik miskin. Tolak ukur kondisi spiritual dapat dilihat dari tiga aspek, yaitu: sholat, puasa dan infak. Persentase mustahik yang aktif menjalankan ibadah sholat baik sebelum maupun sesudah menerima hibah modal yaitu sebanyak enam puluh persen. Sedangkan mustahik yang tidak aktif menjalankan ibadah sholat 
sejumlah empat puluh persen. Persentase mustahik yang aktif menjalankan ibadah puasa baik sebelum maupun sesudah menerima hibah modal yaitu sebanyak delapan puluh persen. Sedangkan mustahik yang tidak aktif menjalankan ibadah puasa sejumlah dua puluh persen. Persentase mustahik yang aktif menngeluarkan infak setidaknya sekali dalam setahun baik sebelum maupun sesudah menerima hibah modal yaitu sebanyak delapan puluh persen. Sedangkan mustahik yang tidak aktif mengeluarkan infak sejumlah dua puluh persen.

\section{SIMPULAN}

Hasil dari penelitian ini adalah pengelolaan zakat produktif hibah modal belum mampu berjalan secara maksimal. Hal tersebut dapat dilihat dari pengawasan terhadap mustahik yang berhak menerima hibah modal dan pengawasan terhadap perkembangan usaha mustahik masih perlu ditingkatkan lagi. Selain itu, pengelolaan zakat produktif hibah modal yang dilakukan oleh BAZNAS Kota Mojokerto masih belum mampu meningkatkan kesejahteraan mustahik miskin secara signifikan baik secara material maupun spiritual. Hal tersebut dapat dilihat dari pendapatan empat mustahik yang berstatus tetap dari sepeluh mustahik yang dijadikan sampel. Bahkan dari sisi spiritual, hibah modal belum mampu meningkatkan kesejahteraan mustahik. Hal tersebut dapat dilihat dari tidak adanya perubahan spiritualitas dari sebelum dan sesudah mendapatkan hibah modal. 


\section{DAFTAR PUSTAKA}

Ahmadi, Rulam. 2016. Metodologi Penelitian Kualitatif. Yogyakarta: Ar-Ruzz Media

Al-Ghazi, Muhammad bin Qasim. 2012. Fiqh Idola Terjemahan Fathul Qarib. Terjemahan Abu Hazim Mubarak. Kediri: MUKJIZAT

Beik, Irfan Syauqi dan Laily Dwi Arsyianti. 2017. Ekonomi Pembangunan Syariah. Jakarta: PT RajaGrafindo Persada

Bungin, Burhan. 2015. Metodologi Penenlitian Sosial dan Ekonomi. Jakarta: Prenadamedia Group

Firdaus, Muhammad, Irfan Syauqi Beik, Tonny Irawan dan Bambang Juanda. 2012. Economic Estimation and Determinations of Zakat Potential in Indonesia. islamic Research and Training Institute. (Online), WP\#1433-07

Iskandar. 2010. Metodologi Penelitian Pendidikan dan Sosial (Kuantitatif dan Kualitatif).Jakarta: Gaung Persada Press

Karim, Adiwarman A. 2010. Sejarah Pemikiran ekonomi Islam. Jakarta: Rajawali Pers

Karimah, Asma. 2017. Efektivitas PendayagunaanZakat Produktif pada Program Pemberdayaan Ekonomi Masyarakat. Skripsi. Jakarta Fakultas Ekonomi dan Bisnis

Kuswarno, Engkus. 2009. Metodologi Penelitian Komunikasi Fenomenologi. Widya Padjadjaran

Larasati, Dewi Citra dan Muhammad Okto Adhittama. 2017. Monitoring dan Evaluasi Program Dana Desa (DD) Sesuai dengan UU Nomor 6 Tahun 2014 Tentang Desa (Studi di Desa Landungsari Kecamatan Dau Kabupaten Malang Jawa Tmur). REFORMASI. (Online), Volume 7 N0. 2

Moleong, Lexy J. 2016. Metodologi Penelitian Kualitatif. Bandung: PT. Remaja Rosdakarya Offset

Outlook BAZNAS Kota Mojokerto Tahun 2012-2017

Qardhawi, Yusuf. 2007. Hukum Zakat. Bogor: Pustaka Litera AntarNusa

Ramadhanu, Andika. 2016. Peran Lembaga Amil Zakat (LAZ) Baitul Maal Hidayatullah (BMH) dalam Pemberdayaan Ekonomi Mualaf Suku Tengger. Skripsi. Surabaya Fakultas Ekonomi dan Bisnis 
(P-ISSN : 2461-0577 ; E-ISSN : 2477-5347)

Rianto, Al Arif M. Nur. 2012. Lembaga Keuangan Syariah. Bandung: CV.

Pustaka Setia

Sodikun, Bagus Imam. 2017. Starategi Pengelolaan Zakat Produktif pada Badan Amil Zakat Nasional (BAZNAS) Kota Mojokerto dalam Meningkatkan Kesejahteraan Mustahik. Skripsi. Surabaya Fakultas Ekonomi dan Bisnis Wibisono, Yusuf. 2015. Mengelola Zakat Indonesia. Jakarta: Kencana Prenada Media Group 